\title{
Idiopathic dilated episcleral vessels (Radius-Maumenee syndrome): case report
}

\author{
Dilatação idiopática dos vasos episclerais (síndrome de Radius-Maumenee): relato de caso
}

Ricardo Alexandre Stock ${ }^{1}$, Natalie lucas Fernandes², Nathan lopes Pastro², Rafaela Santini de Oliveira², Elcio Luiz Bonamigo ${ }^{3}$

\begin{abstract}
Radius-Maumenee syndrome comprises idiopathic dilated episcleral vessels that are usually associated with glaucoma. The case described herein is of a male patient, 69 years old, with chronic dilation of the episcleral vessels and glaucoma in his left eye, with no history of systemic disease. Visual acuity and fundoscopy were normal in both eyes. Tonometry measured $14 \mathrm{mmHg}$ in the right eye and $25 \mathrm{mmHg}$ in the left. Computed tomography angiography (CTA) was negative fo carotid-cavernous fistula. The intraocular pressure of the left eye decreased to $20 \mathrm{mmHg}$ with clinical treatment without regression of episcleral venous dilation. Trabeculectomy normalized the intraocular pressure and reduced the vessels There was choroidal effusion on day 16 of the postoperative period, which resolved with corticosteroids. Although choroidal effusion can occur, the efficacy of trabeculectomy in controlling glaucoma and the reduction of episcleral vessels are clearly demonstrated.
\end{abstract}

Keywords: Eye abnormalities/diagnosis; Glaucoma open-angle/surgery; Eye health; Sclera/blood supply; Venous pressure;Veins/pathology; Syndrome; Varicose veins; Angiography; Ocular physiological processes; Humans; Male; Aged; Case report

\section{RESUMO}

A síndrome de Radius-Maumenee consiste na dilatação idiopática dos vasos episclerais geralmente associada ao glaucoma. Descreve-se o caso de paciente masculino, 69 anos, portador de dilatação crônica dos vasos episclerais e glaucoma do olho esquerdo, sem histórico de doença sistêmica. A acuidade visual e fundoscopia apresentaram-se normais em ambos os olhos. A tonometria mediu $14 \mathrm{mmHg}$ no olho direito e $25 \mathrm{mmHg}$ no esquerdo. A angiotomografia foi negativa para fístula carotídeo-cavernosa. A pressão intraocular do olho esquerdo diminuiu para $20 \mathrm{mmHg} c 0 \mathrm{~m}$ tratamento clínico, sem regressão da dilatação venosa episcleral. A trabeculectomia normalizou a pressão intraocular e reduziu os vasos. Houve efusão coroidiana no 160 dia de pós-operatório que regrediu com corticoterapia. Embora possa ocorrer efusão coroidiana, destaca-se a eficácia da trabeculectomia no controle do glaucoma e na redução dos vasos episclerais.

Descritores: Anormalidades do olho/diagnóstico; Glaucoma de ângulo aberto/ cirurgia; Saúde ocular; Esclera/irrigação sanguínea; Pressão venosa; Síndrome; Varizes; Angiografia; Processos fisiológicos oculares; Humanos; Masculino; Idoso; Relato de caso

\section{INTRODUCTION}

Radius-Maumenee syndrome was identified for the first time in 1978 by the two ophthalmologists who gave their names to the disease ${ }^{(1)}$. The characteristic clinical picture of this syndrome is idiopathic dilated episcleral vessels associated with increased intraocular pressure.

The authors ${ }^{(1)}$ presented a report of four cases of idiopathic dilated episcleral vessels in the absence of carotid-cavernous fistulas, obstructive orbital lesions or hemangiomatosis, which at the time were the diseases that explained such occurrences. Three of the four patients presented with increased unilateral intraocular pressure, corresponding to unilateral open-angle glaucoma. In these patients, intraocular pressure was controlled by surgery. The authors hypothesized that a congenital vascular anomaly was the cause of this ocular manifestation. Subsequently, other cases have been published, with several theories seeking to explain the occurrence of the syndrome.

This manuscript describes the case of a patient with Radius-Maumenee syndrome whose glaucoma and episcleral dilation were controlled by trabeculectomy.

\section{CASE REPORT}

A male patient, aged 69 years old, was admitted to the ophthalmology service with chronic hyperemia of the left eye, which was unresponsive to medical treatment, without other ocular symptoms (Figure 1). He had normal cranial tomography. In his first assessment in 2008, the patient presented with 20/20 visual acuity bilaterally and with normal fundoscopy, without dilation or increased tortuosity of the retinal vessels, as demonstrated by retinography (Figure 2). The intraocular pressure measurement was $14 \mathrm{mmHg}$ in the right eye and $25 \mathrm{mmHg}$ in the left eye, which had dilated episcleral vessels. Biomicroscopy of the left eye showed increased tortuosity and venous engorgement of the conjunctiva and episclera. The patient was treated with antiglaucoma eye drops, which reduced the intraocular pressure to $20 \mathrm{mmHg}$. The episcleral vessel dilation persisted, and CT angiography, obtained to investigate the possibility of arteriovenous fistula, was negative (Figure 3).

Due to the presence of glaucoma, tortuosity, episcleral venous engorgement and negative tests for other possible diseases, the clinical diagnosis of idiopathic dilated episcleral vessels (Radius-Mau-
Submitted for publication: February 1, 2013

Accepted for publication: May 8, 2013

Work conducted at the University of West Santa Catarina, Universidade do Oeste de Santa Catarina UNOESC - Joaçaba campus (SC), Brazil

${ }^{1}$ Professor of Ophthalmology at Universidade do Oeste de Santa Catarina - UNOESC - Joaçaba campus (SC), Brazil.

Academic, Course of Medicine, Universidade do Oeste de Santa Catarina - UNOESC - Joaçaba campus (SC), Brazil.

Ophthalmologist and professor at Universidade do Oeste de Santa Catarina - UNOESC - Joaçaba

campus (SC), Brazil.
Funding: No specific financial support was available for this study.

Disclosure of potential conflicts of interest: R.A.Stock, None; N.L.Fernandes, None; N.L.Pastro, None; R.S.Oliveira, None; E.L.Bonamigo, None.

Correspondence address: Elcio Luiz Bonamigo. Rua Francisco Lindner, 310 - Joaçaba (SC) 89600-000 - Brazil - E-mail: elcio.bonamigo@unoesc.edu.br

Study approved by Research Ethics Committee/Investigational Review Board of the University of the West of Santa Catarina, under the number 40191 
menee syndrome) was confirmed in the left eye, and as a treatment option, a trabeculectomy was performed. On the first day of the postoperative period, the intraocular pressure decreased to $9 \mathrm{mmHg}$. Episcleral vessels showed gradual regression in the days that followed. However, on the $16^{\text {th }}$ day after surgery, choroidal detachment occurred, which was completely reversed using systemic and topical steroids. After stabilization, the intraocular pressure remained at $12 \mathrm{mmHg}$ and the visual acuity at 20/20, with complete regression
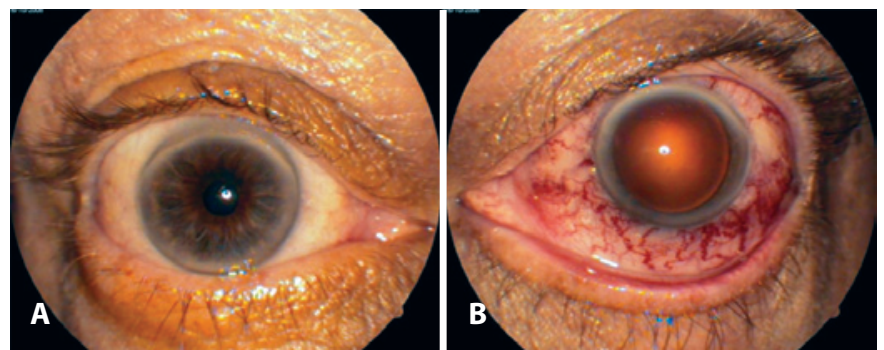

Figure 1. Clinical appearance of the eyes in the preoperative showing episcleral dilated veins of the left eye (B).

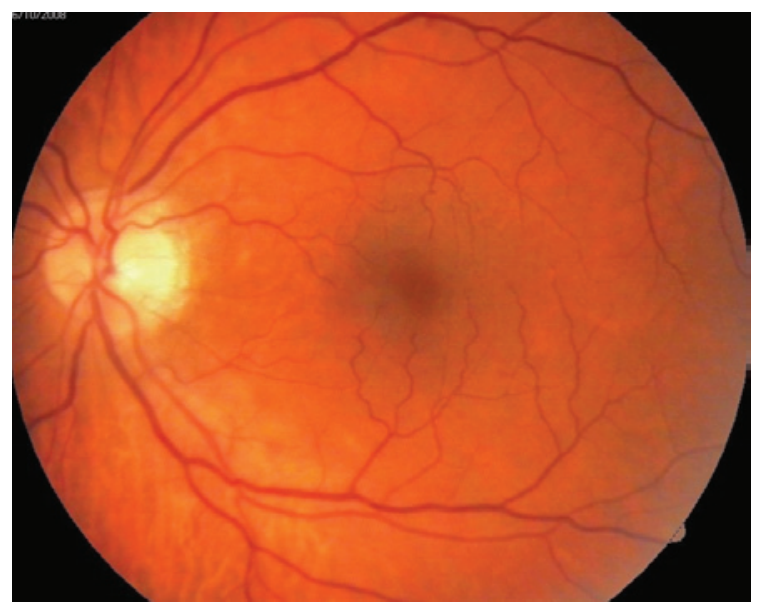

Figure 2. Retinography of the left eye showing uremarkable fundoscopy of the left eye.

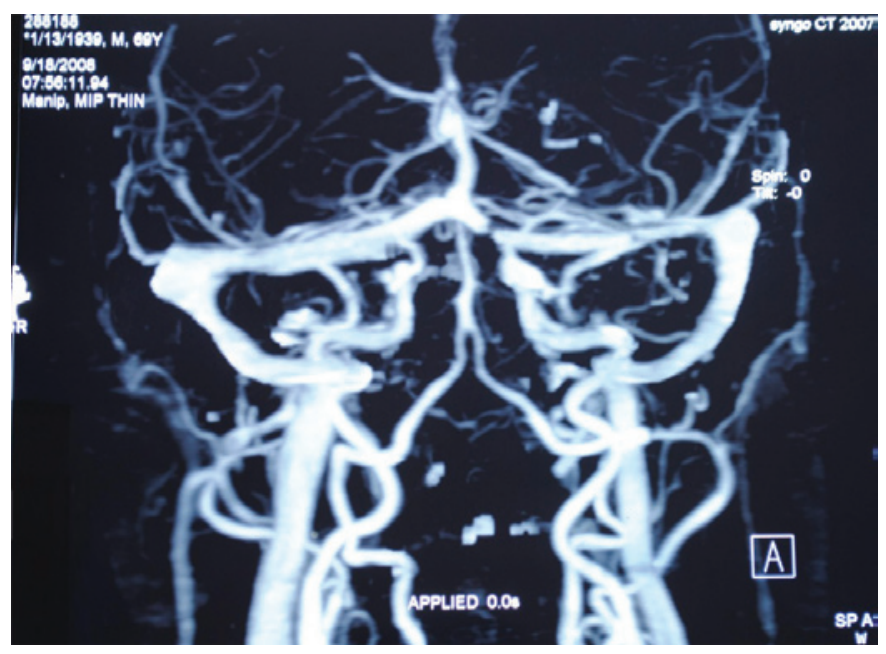

Figure 3. CT Angiography within the normality. of the signs and symptoms caused by the dilated episcleral vessels (Figure 4).

\section{DISCUSSION}

Increased intraocular pressure, which is often associated with ocular injections and dilated episcleral vessels, can occur for several reasons, arteriovenous fistulas being the most common. However, the discovery of Radius-Maumenee syndrome, an unusual clinical picture that presents identical symptoms, means that its inclusion among differential diagnoses should always be considered.

The diagnosis of Radius-Maumenee syndrome is based on clinical findings characteristic of episcleral vessel dilation and increased intraocular pressure, corresponding to a picture of open-angle glaucoma. In this case, arteriography was used to detect the presence of arteriovenous fistulas, which are the most common cause of dilated episcleral vessels ${ }^{(2)}$, but the result was normal. Other tests, including neuro-imaging examination, orbital venography and angiography, were also negative. Although the pathogenesis of this condition remains obscure, it is believed that the presence of abnormal pressure in blood drainage could explain the emergence of the condition ${ }^{(3)}$. One hypothesis to explain the difficulty of venous return involves the hyalinization of Schlemm's canal, which causes distal obstruction of the anterior chamber ${ }^{(4)}$.

Radius-Maumenee syndrome thus occurs due to a poor venous drainage of ocular episcleral vessels. The difficulty in establishing an early diagnosis can cause negative effects on visual function in the affected eye due to an increase in secondary intraocular pressure and its consequent damage to the optic nerve ${ }^{(5)}$.

Intraocular pressure is dependent on the rate of aqueous humor production and drainage of the episcleral veins. Increased intraocular pressure and visual field loss due to optical impairment can be the result of the increased pressure of these vessels ${ }^{(6)}$. Possible causes include venous obstructions (venous sinus thrombosis and superior vena cava syndrome), arteriovenous shunts or fistulas, Sturge-Weber syndrome, scleritis, orbital diseases related to thyroidopathy and orbital tumors. Radius-Maumenee syndrome presents as an uncommon entity with a characteristic clinical presentation, and therefore, it should be included among diagnostic possibilities. The finding of episcleral vessel dilation in non-inflamed eyes constitutes a warning to the ophthalmologist of possible glaucoma ${ }^{(4)}$.

Glaucoma surgeries, such as trabeculectomy, sclerectomy and sinusotomy, performed at the appropriate time, can provide good treatment results, although they do not always result in the reduction of episcleral vessels ${ }^{(7)}$. During the postoperative period, as in this case, there can be more frequent choroidal effusion than normal( ${ }^{(8)}$. Sinusotomy is a surgical procedure effective in treating Radius-Maumenee syndrome, and its early realization prevents damage to the optic nerve ${ }^{(9,10)}$

This report highlights the need to investigate the diagnosis of Radius-Maumenee syndrome in patients with glaucoma and epis-
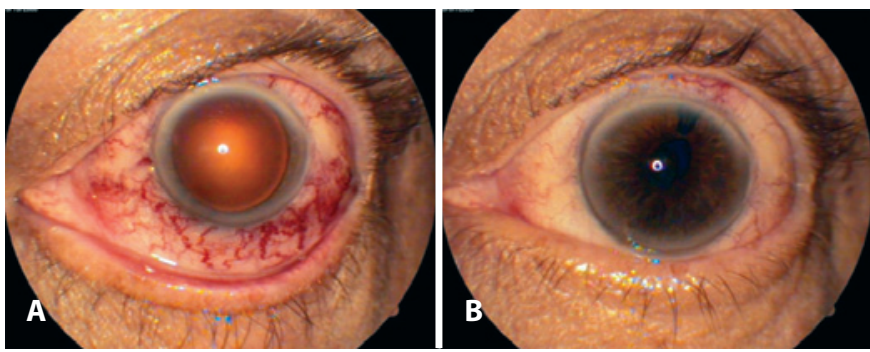

Figure 4. Clinical appearance of the preoperative $(A)$ and eight months after surgery (B) showing the reduction of the episcleral veins. 
cleral vessel dilation, as well as the benefits of glaucoma surgery in the resolution of clinical symptoms, although choroidal effusion can occur in the postoperative period.

\section{REFERENCES}

1. Radius RL, Maumenee E. Dilated episcleral vessels and open-angle glaucoma. Am J Ophthalmol. 1978;86(1):31-5

2. Foroozan R, Buono LM, Savino PJ, Sergott RC. Idiopathic dilated episcleral veins and increased intraocular pressure. Br J Ophthalmol. 2003;87(5):652-3.

3. Grieshaber MC, Dubler B, Knodel C, Killer HE, Flammer J, Orgül S. Retrobulbar blood flow in idiopathic dilated episcleral veins and glaucoma. Klin Monbl Augenheilkd [Internet] 2007[cited 2012 Jan 2];224(4):320-3. Available from: https://www.thiemeconnect.com/ejournals/html/10.1055/s-2007-962946

4. Lanzl IM, Welge-Luessen U, Spaeth GL. Unilateral open-angle glaucoma secondary to idiopathic episcleral veins dilated. Am J Ophthalmol. 1996;121(5):587-9.
5. Acaroglu G, Eranil S, Ozdamar Y, Ural F, Teke Y. Idiopathic episcleral venous engorgement. Clin Exp Optom. 2009:92(6):507-10.

6. Jyothi PT, Bindus S, Shimna I. Radius-Maumenee Syndrome - a case report. Kerala J Ophthalmol [Internet]. 2011[cited 2012 Nov 21];23(2):152-4. Available from: http:// ksos.in/ksosjournal/journalsub/Journal_Article_24_415.pdf

7. Otulana TO, Onabolu OO, Fafiolu VO. Unilateral idiopathic dilated episcleral vein with secondary open angle glaucoma (Radius-Maumenee Syndrome) in an African - a case report and literature review. Niger J Ophthalmol. 2008;16(1):20-2.

8. Parikh R, Desai S, Kothari K. Dilated episcleral veins with secondary open angle glaucoma. Indian J Ophthalmol. 2011;59(2):153-5.

9. Groh MJ, Kuchle M. [Idiopathic episcleral venous stasis with secondary open-angle glaucoma (Radius-Maumenee-Syndrom). Klin Monatsbl Augenheilkd. 1997;211(2): 131-2. German.

10. Lämmer R. [Secundary open angle glaucoma with idiopathic episcleral venous pressure (Radius-Maumenee syndrome). Sinus-otomy as operative preocedure of choice]. Ophthalmologe. 2007;104(6):515-6. Comment on: Ophthalmologe. 2007;104(6): 513-4. German. 